\section{FURTHER INVESTIGATIONS ON XENIA IN MAIZE.}

PROBABLY few botanical discoveries of recent years have aroused more interest than the remarkable observations of Nawaschin upon the fusion of one of the generative nuclei of the pollen tube with the definitive nucleus of the embryo sac. Since further investigations have rendered it not improbable that the process is of general occurrence, its bearing upon some curious phenomena met with in hybrids is of great interest as affording an explanation, not only as to how hybrid embryos, but also how truly hybrid endosperms can be produced by crossing different races of plants. De Vries' beautiful observations upon maize, which were made almost simultaneously with those of Correns, have already formed the subject of an article in this journal, and they have recently been considerably extended by some experiments conducted by Webber 1 in America. As a result of his investigations, Webber concludes, in all cases in which the hybrid corn shows a change of colour, that this is due to the endosperm alone, the translucent pericarp retaining, as might have been theoretically anticipated, the character properly appertaining to the corn of the female parent. But in a large number of instances it was found that, although the embryo on germination showed that hybridisation had occurred, there was no evidence of the transference of the qualities of the male parent to the accompanying endosperm. On the other hand, in some hybrid corns the endosperm exhibited a spotted appearance, which might even (e.g. when Gilman Flint was crossed with Stowell's Evergreen) be restricted to only a portion of its substance. The author suggests that the former case might be explained as being the result of failure on the part of the generative nucleus to unite with any nucleus within the embryo sac. The spotted endosperms, on the other hand, might be due to an independent segmentation of the second pollen nucleus, which had failed to unite with the polar nuclei, in which case the portion of endosperm so arising might be expected to retain the characters of the male parent.

There is no inherent improbability in such a suggestion, nor need it necessarily affect any views which may be entertained as to the sexuality of the fusion which we are (perhaps rather hastily) beginning to regard as general; the investigations of Boveri and of Hertwig respectively have shown that the nuclei of both male and female reproductive cells of sea-urchins can be made to segment by appropriate means, and even produce larva, and this without any preceding fusion of the sexual cells themselves.

It is clear, however, that much more investigation is required before the points raised by Dr. Webber can be cleared up, but it is to be hoped that so promising a field of research will not be left to lie fallow, although the work itself will necessarily prove arduous.

\section{PORTABLE GAS PRODUCERS.}

A IR-GAS, as it is popularly called, consists of an admixture of ordinary atmospheric air with the vapour of one of the volatile hydrocarbons, such as pentane, gasolene or petroleum spirit. Travellers and others having called attention to the production of a natural gas in the petroleum-bearing districts, as at Baku and elsewhere, it was not long before attempts were made to imitate the workings of nature by producing from the petroleum of commerce a combustible gas. The carburetting of ordinary air by forcing a clirrent over liquid petroleum first seems to have been proposed by Lowe in 1831, as in that year he took out a patent for his apparatus.

"Xenia, or the Immediate Effect of Pollen in Maize," by Herbert J. Webber, U.S. Department of Agriculture, Bulletin 22, Washington, NO. $16: 6$, vOL. 62$]$
Air-gas producers may be roughly classified as follows :-

(1) Apparatus in which air is forced under pressure either through or over liquid petroleum, in which class mention may be made of the apparatus of Jackson, Müller, Weston and Maxim.

(2) Apparatus in which, on account of the danger of using large quantities of liquid petroleum, an absorbent is used to take up the hydrocarbon, either in part or entirely, the air being, as in the first case, forced under pressure over or through the absorbent.

Considerable commercial importance attaches to certain of the apparatus mentioned under the two classes given above, both the "Alpha" apparatus of Muller and the "Sun" apparatus of Hearson having had a considerable success, both here and in America, for the lighting of country houses and the like. It will be easily seen, however, that the necessity of having some motive power to actuate the current of air introduces complex mechanism which militates against the general adoption of such apparatus. This disadvantage has, however, been met by the apparatus comprising the third and last class of

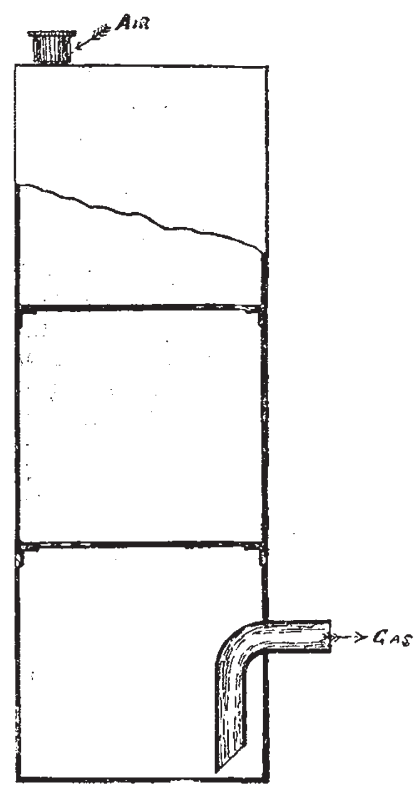

FIG. 3.

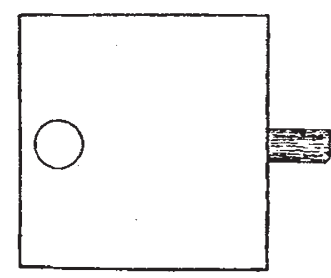

FIG. 2.

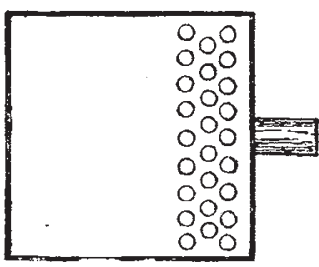

FIG. 3. aero-gas generators, which possess a peculiar interest on account of their simplicity and efficiency.

In $1895 \mathrm{Mr}$. Naum Notkin, of Moscow, was struck with the idea that use might be made of the physical property that carburetted air is considerably heavier than ordinary atmospheric air for the construction of a gas-producing apparatus of extreme simplicity. His method and apparatus, which are patented in Great Britain (No. 20667/94), may be described as follows :-

The apparatus consists essentially of a vessel of tin or other material, with an orifice at the top and another at the bottom. This simple vessel is filled with a porous material which is impregnated from time to time with one of the lighter hydrocarbons, and this constitutes the whole apparatus. The action of the apparatus is that ordinary atmospheric air enters at the upper orifice, and taking up a certain proportion of hydrocarbon vapour becomes heavier and gravitates through the mass of absorbents, taking up more and more of the hydrocarbon vapour, until it finally issues from the lower orifice in the form of a gas capable of lighting, heating, and all other uses to which ordinary gas is put. Not only does the 